Rapid elimination from blood circulation and urinary excretion may be desirable from a toxicological point of view, but perhaps undesirable therapeutically when the aim is to achieve biological activity at specific diseased sites. Therefore, a balance between longer blood circulation and maintenance of renal excretion should be envisaged as one of the optimal (but challenging) strategies for the design of transporters based on carbon nanotubes. In a broader context, considering our accumulating knowledge on the pharmacokinetics of carbon nanotubes and that of other filamentous nanomaterials ${ }^{11,12}$, it is evident that the blood flow kinetics and transport mechanisms of these high-aspect-ratio materials are very different from those of spherical nanoparticles.

Overall, the wealth of design options that are offered by different engineered nanomaterials, for example by controlling shape, size, surface properties and molecular weight, makes it possible to fabricate materials that interact in widely differing ways with biological matter. Along this principle, specific features can be included on nanotubes and other fibrillar nanostructures to achieve certain biological activities and eventually therapeutic or diagnostic outcomes.

Kostas Kostarelos is at the Nanomedicine Lab, Centre for Drug Delivery Research, The School of Pharmacy, University of London,
29-39 Brunswick Square, London WC1N 1AX, United Kingdom.

e-mail: kostas.kostarelos@pharmacy.ac.uk

References

1. Ruggiero, A. et al. Proc. Natl Acad. Sci. USA 107, 12369-12374 (2010)

2. Kostarelos, K. et al. Nature Nanotech. 2, 108-113 (2007).

3. Haraldsson, B., Nystrom, J. \& Deen, W. M. Physiol. Rev. 88, 451-487 (2008).

4. Singh, R. et al. Proc. Natl Acad. Sci. USA 103, 3357-3362 (2006)

5. Lacerda, L. et al. Adv. Mater. 20, 225-230 (2008).

6. Lacerda, L. et al. Small 4, 1130-1132 (2008).

7. Liu, Z., Tabakman, S., Welsher, K. \& Dai, H. Nano. Res, 2, 85-120 (2009)

8. Deng, X. et al. Carbon 45, 1419-1424 (2007)

9. Cedervall, T. et al. Proc. Natl Acad. Sci. USA 104, 2050-2055 (2007)

10. Kostarelos, K. Nature Biotechnol. 26, 774-776 (2008).

11. Geng, Y. et al. Nature Nanotech. 2, 249-255 (2007).

12. Park, J. H. et al. Small 5, 694-700 (2009).

\section{OYSTER GLUE}

In 1880, Chesapeake Bay was heaven for oyster-lovers, as the native common Eastern oyster Crassostrea virginica was hauled ashore in about a hundred times the quantities now harvested. But over-fishing has so devastated the population that non-native varieties have lately been introduced, albeit with little success.

It's the same story the world over. Along the coasts of Europe and Australia too, oyster populations have been reduced to less than 10 percent of their historical abundance ${ }^{1}$. This is not just a gastronomic disaster, for oyster reefs - agglomerated mounds of billions of oyster shells - are a vital component of estuarine and coastal marine ecosystems. The reefs harbour other aquatic organisms, filter the sea water, and help protect the coastline from storms. The shift in the ecological balance has also led to eutrophication of estuarine waters.

Last year brought a ray of light to this gloomy picture, when researchers reported that artificial reefs constructed since 2004 in estuarine sanctuaries in Chesapeake Bay from the shells of native $C$. virginica dumped by the US Army Corps of Engineers have helped to boost oyster populations ${ }^{2}-$ not to the levels of a century ago, but enough to demonstrate the potential of the method.

This study showed that the higher the artificial reef (the highest were up to $45 \mathrm{~cm}$ above the river bottom), the more effectively it stimulated oyster growth. Reefs are not, however, simply piles of old shells: they have a complex architecture in which shells are bonded together by material excreted by the living oysters. The research showed that the long-term stability of a reef depends crucially on whether it acquires enough cohesion from this cement.

That's why a new study of the adhesive used for oyster-reef construction could prove so important. Burkett et al. have analysed the chemical composition of this material in C. virginica reefs offshore from South Carolina ${ }^{3}$. They find that it is an organic-inorganic composite made up mostly of calcium carbonate deposited within a matrix of phosphorylated protein.

There is less of the mineral in the adhesive (about 20 percent) than in the oyster shells (about 30 percent), and moreover it is a mixture of the polymorphs calcite and aragonite in the ratio $2: 1$, whereas the shell is mostly calcite. So the inorganic component of the adhesive is clearly tailor-made. And the glue as a whole is very different from that used by mussels and barnacles to stick to surfaces, which is mostly protein. Mussel adhesive proteins in particular have inspired biomimetic efforts to create resilient polymeric

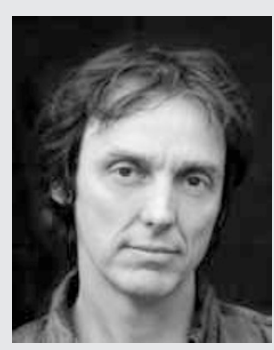

PHILIP BALL

adhesives ${ }^{4}$. Both these and barnacle glues (which are less well understood) are strongly hydrated, whereas the inorganic-organic material of oysters has only a tenth of the water content of barnacle adhesive.

As well as suggesting a new strategy for biologically inspired adhesion - and, on the other hand, for preparing antifouling coatings for marine structures - the new findings might offer critical information for promoting the integrity of artificial reefs, which could become central to restoring this vital component of coastal ecology.

References

1. Kirby, M. X. Proc. Natl Acad. Sci. USA 101, 13096-13099 (2004).

2. Schulte, D. M., Burke, R. P. \& Lipcius, R. N. Science 325, 1124-1128(2009).

3. Burkett, J. R., Hight, L. M., Kenny, P. \& Wilker, J. J. J. Am. Chem. Soc. 132, 12531-12533 (2010).

4. Lee, B., Dalsin, J. \& Messersmith, P. in Biological Adhesives (eds Smith, A. M. \& Callow, J. A.) 257-278 (Springer, 2006). 